JGG 2021;69:262-264

doi: 10.36150/2499-6564-N455

Clinical Geriatrics - Reviews

\title{
Nephropathy and chronic renal insufficiency
}

\author{
Nicola Napoli, Flavia Tramontana
}

Department of Endocrinology and Diabetology, Campus Bio-Medico University, Rome, Italy; Italian

Society of Gerontology and Geriatrics, Florence, Italy; Italian Society of Diabetology, Rome, Italy

\section{RECOMMENDATIONS}

A. All patients with diabetic nephropathy should be considered as having high cardiovascular risk and should undergo treatment to modify all related risk factors (grade $4 \mathrm{~A})^{1}$.

B. Blood pressure targets for patients with micro- and macro-albuminuria should be $<130 / 80 \mathrm{mmHg}$ (grade $4 \mathrm{~A})^{2}$.

C. Older DM patients should be screened for kidney disease using yearly albuminuria measurement (grade $4 \mathrm{~A})^{3}$.

D. The recommended method to evaluate albuminuria is to measure the albumin-to-creatinine ratio in a spot urine sample ${ }^{3}$. Serum creatinine should be measured annually independent of urinary albumin levels ${ }^{1}$.

E. Estimated glomerular filtration rate (eGFR) should be calculated according to the Chronic Kidney Disease Epidemiology Collaboration (CKD-EPI) equation, in line with international recommendations and should be assessed at least once a year ${ }^{3}$.

Received: July 30, 2021

Accepted: September 16, 2021

\section{Correspondence}

Nicola Napoli

Department of Endocrinology and Diabetology,

Campus Bio-Medico University, via Alvaro del

Portillo 21, 00128 Rome, Italy

E-mail: n.napoli@unicampus.it

How to cite this article: Napoli N, Tramontana F. Nephropathy and chronic renal insufficiency. Journal of Gerontology andGeriatrics2021;69:262-264.https://doi. org/10.36150/2499-6564-N455

(C) Copyright by Società Italiana

di Gerontologia e Geriatria (SIGG)

\section{(c) (1) $(9$}

This is an open access article distributed in accordance with the CC-BY-NC-ND (Creative Commons Attribution-NonCommercial-NoDerivatives 4.0 International) license. The article can be used by giving appropriate credit and mentioning the license, but only for non-commercial purposes and only in the original version. For further information: https://creativecommons.org/licenses/by-nc-nd/4.0/deed.en

F. Drugs associated with lower risk of hypoglycemic events should be preferred, such as: metformin (if not contraindicated due to reduced eGFR), DPP-IV inhibitors, SGLT2-i, pioglitazone, GLP-1RA, or their combinations (grade $2 A)^{1}$. If sulfonylureas are to be used, gliclazide should be preferred because it is associated with a lower risk of hypoglycemia compared to other drugs in this class (grade 2A) ${ }^{1}$. Although repaglinide is not excreted by kidney, its use in the elderly should be avoided because of the lack of studies in geriatric patients and the risk of hypoglycemia. In addition, the dose of repaglinide should be halved in patients with $\mathrm{CrCl}<30 \mathrm{ml} / \mathrm{min}$. Repaglinide is not indicated in patients with end-stage kidney disease. Metformin use can be considered with caution in patients with an eGFR up to $30 \mathrm{ml} / \mathrm{min} / 1.73 \mathrm{~m} 2$, taking also into account risk factors for kidney function decline (grade 1A). In elderly patients treated with metformin, eGFR should be monitored at least once a year as well as at every dose increase (grade 1A).

\section{STRENGTH OF THE RECOMMENDATIONS}

The quality of the evidence is high. Recommendations are supported by published evidence.

\section{SUPPORTING EVIDENCE}

See appendix. 


\section{AREAS OF UNCERTAINTY AND FUTURE PERSPECTIVES}

Recent clinical trials on GLP-1RA and SGLT2 inhibitors have shown a significant protective effect of these drugs on kidney function, delaying the onset of nephropathy. However, evidence in elderly patients is limited and further studies are needed. SGLT2 inhibitors should be used with caution in the elderly given the risk of urinary and genital infections.

\section{APPENDIX}

Diabetic nephropathy occurs in $20-40 \%$ of T2DM patients ${ }^{3}$, especially in adults aged $>70$ years. Older people are generally more affected by renal disorders, which are diagnosed in about 25\% of people aged 65 74 years and over $50 \%$ of those aged $\geq 70$ years ${ }^{4,5}$. The term "diabetic kidney disease" (DKD) is used to describe heterogeneous types of kidney damage that can arise during the natural history of $\mathrm{DM}^{6}$. A reduction in GFR and/or the presence of increased urinary albumin excretion for at least three months are the main clinical characteristics of renal damage in DM patients. These conditions often occur together but there may also be situations where an increase in albuminuria is seen without a drop in GFR or where GFR decreases without a change in urinary albumin excretion ?

DKD can begin with micro-albuminuria, which can then progress to macro-albuminuria. Therefore, diabetic nephropathy screening is generally carried out using an assessment of micro-albuminuria and eGFR with validated tools such as the Chronic Kidney Disease Epidemiology Collaboration (CDK-EPI) ${ }^{3}$ equation. In Italy, the prevalence of micro- and macro-albuminuria in patients with DM is between 27 and $34 \%{ }^{1}$. Patients with macro-albuminuria ( $\geq 300 \mathrm{mg} / 24$ hours) are highly likely to develop endstage kidney disease within a few years. A recent metaanalysis on approximately 30,000 individuals showed that variations in albuminuria can be used as a proxy for DKD progression ${ }^{8}$. Although progression to end-stage kidney disease is a major concern, cardiovascular disease (CVD) is another important issue. Indeed, it has long been known that kidney failure due to any cause is associated with a 2-4 fold increase in the risk of CVD morbidity and mortality, independent of the presence of well-established CVD risk factors ${ }^{9}$. Patients with chronic kidney disease are more likely to die from cardiovascular events than for end-stage kidney disease. In patients with an eGFR $\leq 60 \mathrm{~mL} / \mathrm{min} / 1.73 \mathrm{~m}^{2}$, the risk of experiencing a cardiovascular event may be up to ten times higher than the risk of developing end-stage kidney disease ${ }^{10,11}$. The risk of cardiovascular events increases so much that both reduced eGFR and increased albuminuria have been recognized as independent risk factors for cardiovascular mortality ${ }^{12}$ In particular, a $0.4 \mathrm{mg} / \mathrm{mmol}$ increase in urine albumin/ creatinine ratio (ACR) corresponds to a $5.9 \%$ increase in the risk of developing a cardiovascular event ${ }^{13}$. Patients with chronic kidney disease are also at increased risk of hypoglycemia ${ }^{14,15}$, which further contributes to increased cardiovascular mortality and morbidity ${ }^{16}$. There are several reasons why chronic kidney disease is associated with an increase in hypoglycemic events: i) the counterregulatory response to hypoglycemia is blunted, and renal gluconeogenesis is impaired mainly due to a reduced kidney mass that results in a reduced ability to release glucose; ii) there is a reduction in the kidney's insulin clearance capacity. Reducing the risk of hypoglycemia is one of the main therapeutic targets in elderly, frail DM patients, who are already at risk of falls. For this reason, particular care should be taken when choosing the antidiabetic drugs to be used in elderly DM patients with kidney damage. Glucose-lowering drugs such as sulfonylureas should be avoided, as exacerbating the risk of hypoglycemia may increase the occurrence of adverse clinical events (angina, arrhythmias, falls). The use of pioglitazone also requires careful clinical evaluation, as adverse events, including a reduction in bone mass and increased risk of heart failure make it a potentially unsuitable pharmacological therapy for older persons, especially those over 75 years of age. Among the available DPP-4 inhibitors, linagliptin does not need dose adjustment because its renal clearance is minimal renal, while dosage of others drugs in this class that needs to be adjusted according to eGFR.

Some drugs such as SGLT2-i have a significantly positive effect on kidney function. For example, two randomized-controlled studies (CANVAS and CREDENCE) have shown that treatment with canagliflozin in patients with T2DM leads to a greater reduction in annual albuminuria progression and less loss of kidney function than placebo ${ }^{16,17}$. In addition, the LEADER and SUSTAIN-6 studies have shown a potential positive effect of Glucagon-Like Peptide-1 Receptor Agonists (GLP-1RAs), such as liraglutide and semaglutide, which are associated with a $22 \%$ reduction in the incidence of nephropathy and a $26 \%$ decrease in kidney disease progression ${ }^{18,19}$. The REWIND study reported a 40$50 \%$ reduction in eGFR decline in patients administered dulaglutide ${ }^{20}$.

The UKPDS study showed that improved blood pressure control is associated with a reduction in diabetic nephropathy ${ }^{21}$. The use of ACE-inhibitors in patients with macro-albuminuria leads to a reduction in the progression of albuminuria levels and to slower GFR decline ${ }^{22}$. Angiotensin receptor blockers (ARBs) have also proved to be an effective treatment for diabetic nephropathy as their use is associated a lower progression from micro- to macro-albuminuria ${ }^{23}$. 
Ethical consideration

None.

\section{Acknowledgement}

None.

\section{Funding}

None.

Conflict of interest

Abiogen, Eli-Lilly, UCB

\section{References}

1 Associazione Medici Diabetologi (AMD), Società Italiana di Diabetologia (SID). Standard italiani per la cura del diabete mellito, 2018 (https://www.siditalia.it/pdf/Standard\%20di\%20 Cura\%2OAMD\%20-\%20SID\%202018_protetto2.pdf).

2 Khwaja A. KDIGO clinical practice guidelines for acute kidney injury. Nephron Clin Pract 2012;120:c179-184. https://doi. org/10.1159/000339789

3 American Diabetes Association (ADA). Standards of medical care in diabetes, 2020. Diabetes Care 2020;43(Suppl 1):S37S47. https://doi.org/10.2337/dc20-S004

4 Couser WG, Remuzzi G, Mendis S, et al. The contribution of chronic kidney disease to the global burden of major noncommunicable diseases. Kidney Int 2011;80:1258-1270. https:// doi.org/10.1038/ki.2011.368

5 Hemmelgarn BR, Zhang J, Manns BJ, et al. Progression of kidney dysfunction in the community-dwelling elderly. Kidney Int 2006;69:2155-2161. https://doi.org/10.1038/sj.ki.5000270

6 Doshi SM, Friedman AN. Diagnosis and management of type 2 diabetic kidney disease. Clin J Am Soc Nephrol 2017;12:13661373. https://doi.org/10.2215/cjn.11111016

7 de Boer $\mathbb{H}$, Steffes MW. Glomerular filtration rate and albuminuria: twin manifestations of nephropathy in diabetes. J Am Soc Nephrol 2007;18:1036-1037. https://doi.org/10.1681/ asn.2007020189

8 Heerspink HJL, Greene T, Tighiouart $\mathrm{H}$, et al. Change in albuminuria as a surrogate endpoint for progression of kidney disease: a meta-analysis of treatment effects in randomised clinical trials. Lancet Diabetes Endocrinol 2019;7:128-139. https://doi.org/10.1016/s2213-8587(18)30314-0

9 Gansevoort RT, Correa-Rotter R, Hemmelgarn BR, et al. Chronic kidney disease and cardiovascular risk: epidemiology, mechanisms, and prevention. Lancet 2013;382:339-352. https://doi.org/10.1016/s0140-6736(13)60595-4

10 Eriksen BO, Ingebretsen OC. The progression of chronic kidney disease: a 10-year population-based study of the effects of gender and age. Kidney Int 2006;69:375-382. https://doi. org/10.1038/sj.ki.5000058
11 Bansal N, Katz R, Robinson-Cohen C, et al. Absolute rates of heart failure, coronary heart disease, and stroke in chronic kidney disease: an analysis of 3 community-based cohort studies. JAMA Cardiol 2017;2:314-318. https://doi.org/10.1001/ jamacardio.2016.4652

12 Hemmelgarn BR, Manns BJ, Lloyd A, et al. Relation between kidney function, proteinuria, and adverse outcomes. JAMA 2010;303:423-429. https://doi.org/10.1001/jama.2010.39

13 Gerstein HC, Mann JF, Yi Q, et al. Albuminuria and risk of cardiovascular events, death, and heart failure in diabetic and nondiabetic individuals. JAMA 2001;286:421-426. https://doi. org/10.1001/jama.286.4.421

14 Moen MF, Zhan M, Hsu VD, et al. Frequency of hypoglycemia and its significance in chronic kidney disease. Clin J Am Soc Nephrol 2009;4:1121-1127. https://doi.org/10.2215/ cjn.00800209

15 Alsahli M, Gerich JE. Hypoglycemia, chronic kidney disease, and diabetes mellitus. Mayo Clin Proc 2014;89:1564-1571. https://doi.org/10.1016/..mayocp.2014.07.013

16 Neal B, Perkovic V, Mahaffey KW, et al. Canagliflozin and cardiovascular and renal events in type 2 diabetes. N Engl J Med 2017;377:644-657. https://doi.org/10.1056/nejmoa1611925

17 Perkovic V, Jardine MJ, Neal B, et al. Canagliflozin and renal outcomes in type 2 diabetes and nephropathy. N Engl J Med 2019;380:2295-2306. https://doi.org/10.1056/ nejmoa1811744

18 Mann JFE, Ørsted DD, Brown-Frandsen K, et al. Liraglutide and renal outcomes in type 2 diabetes. $\mathrm{N}$ Engl $\mathrm{J}$ Med 2017;377:839-848. https://doi.org/10.1056/nejmoa1616011

19 Verma S, Bain SC, Monk Fries T, et al. Duration of diabetes and cardiorenal efficacy of liraglutide and semaglutide: a post hoc analysis of the LEADER and SUSTAIN 6 clinical trials. Diabetes Obes Metab 2019;21:1745-1751. https://doi.org/10.1111/ dom.13698

20 Gerstein HC, Colhoun HM, Dagenais GR, et al. Dulaglutide and cardiovascular outcomes in type 2 diabetes (REWIND): a double-blind, randomised placebo-controlled trial. Lancet 2019;394:121-130. https://doi.org/10.1016/ s0140-6736(19)31149-3

21 UK Prospective Diabetes Study Group. Tight blood pressure control and risk of macrovascular and microvascular complications in type 2 diabetes: UKPDS 38. UK Prospective Diabetes Study Group. BMJ 1998;317:703-713.

22 Lewis EJ, Hunsicker LG, Bain RP, et al. The effect of angiotensin-converting-enzyme inhibition on diabetic nephropathy. The Collaborative Study Group. N Engl J Med 1993;329:14561462. https://doi.org/10.1056/nejm199311113292004

23 Lewis EJ, Hunsicker LG, Clarke WR, et al. Renoprotective effect of the angiotensin-receptor antagonist irbesartan in patients with nephropathy due to type 2 diabetes. N Engl J Med 2001;345:851-860. https://doi.org/10.1056/nejmoa011303

\section{This statement is: \\ $凶$ Recommendation (supported by published evidence) $\otimes$ Best practice (supported by expert opinion)}

Quality of the evidence (in the case of recommendation):
$\square$ Low
$\square$ Moderate
$\square$ High

